05

\title{
Анализ влияния физико-механических характеристик материала кумулятивной облицовки на параметры высокоскоростного элемента
}

\author{
(C) В.И. Колпаков, С.В. Ладов, Я.М. Никольская, С.В. Федоров \\ Московский государственный технический университет им. Н.Э. Баумана, \\ 105005 Москва, Россия \\ ฯ e-mail: nikolskayajm@yandex.ru
}

(Поступило в Редакцию 16 апреля 2018 г.)

\begin{abstract}
Представлены результаты численного моделирования процесса взрывного формирования высокоскоростного компактного элемента (ВКЭ) из медных, стальных и алюминиевых кумулятивных облицовок (КО), сочетающих в себе форму полусферического сегмента, плавно переходящего в цилиндрическую поверхность (облицовок типа „полусфера-цилиндр“). Поставленная задача решена в двумерной осесимметричной постановке с учетом предельных параметров динамического напряженно-деформированного состояния, вызывающих пластическое течение и разрушение материала КО, в рамках оригинальной расчетной модели функционирования кумулятивного заряда (КЗ), определяющей индивидуальное влияние отдельных элементов КО, в том числе различие в числовых характеристиках их физико-механических свойств и критических условий разрушения, на конечные параметры ВКЭ. При этом установлено, что пластические свойства материала и критические условия его разрушения не влияют на конечную скорость формируемого ВКЭ, однако оказывают влияние на его форму, размеры и массу.
\end{abstract}

DOI: 10.21883/JTF.2018.12.46784.150-18

При проведении исследований поведения материалов и конструкций в условиях высокоскоростного взаимодействия тел одним из наиболее эффективных методов получения ВКЭ по комплексу критериев, учитывающему массово-скоростные параметры получаемых элементов, габариты метательных устройств, стоимость и трудоемкость проведения экспериментов, является применение К3 с облицовкой комбинированной формы типа полусфера-цилиндр (ПЦ-облицовок) [1-6]. Данные облицовки состоят из двух поверхностей вращения полусферической и цилиндрической. Применение такой формы КО обусловлено возможностью формирования ВКЭ, в котором участвует как струеобразующая полусферическая составляющая облицовки, так и ее цилиндрическая часть, осуществляющая отсечку сформированного ВКЭ. Благодаря простоте и небольшим размерам такого метательного устройства данный способ формирования высокоскоростных элементов получил достаточно широкое распространение на практике. Согласно данным [3], применение ПЦ-облицовок позволило создать систему геометрически подобных КЗ, устойчиво формирующих компактные стальные элементы массой $17-100 \mathrm{~g}$, движущихся со скоростью около $6 \mathrm{~km} / \mathrm{s}$.

Данная задача формирования граммовых ВКЭ является актуальной и имеет практическое значение для моделирования взаимодействия осколков метеороидов и космического мусора с обшивками летательных аппаратов. При этом реалии сегодняшнего дня требуют получения компактных элементов, движущихся со скоростями $10 \mathrm{~km} / \mathrm{s}$ и выше. В работах [5-9] на основе результатов численных расчетов были предложены возможные пути повышения скорости компактных элементов, формируемых при взрывном обжатии стальных ПЦ- облицовок. Идея заключалась в переходе от применения полусферических облицовок постоянной толщины к профилю облицовок различных форм с дегрессивной толщиной КО, т.е. уменьшающейся от вершины к основанию КО. Как было показано в [8,9], при взрывном обжатии таких КО наблюдается увеличение скорости формируемого струйного течения, обусловленное особенностями реализации условий сферической кумуляции (более высокой концентрацией кинетической энергии во внутренних слоях схлопывающейся сферической части оболочки), и, как следствие, более высокой скоростью ВКЭ.

Первоначальное моделирование влияния формы и дегрессивности струеобразующей части осуществлялось без учета критерия разрушения материала облицовки. При этом полученные численным моделированием результаты повышения скорости сформированного ВКЭ полностью подтвердились результатами экспериментальных исследований $[7,10]$.

Проведенные численные расчеты с использованием программного комплекса ANSYS Autodyn с учетом критерия разрушения материала показали, что применительно к стальным КО данный критерий практически не оказывает существенного влияния на скорость сформированного ВКЭ. В настоящей работе проведено более детальное изучение влияния физико-механических свойств материала комбинированной КО на процесс формирования ВКЭ и его массово-скоростные параметры. При этом в качестве материала КО исследуются не только сталь, но и такие материалы, как алюминий и медь, в качестве взрывчатого вещества (BB) принимался высокоэнергетический октогеносодержащий состав. Данный набор материалов определяется актуальностью их 


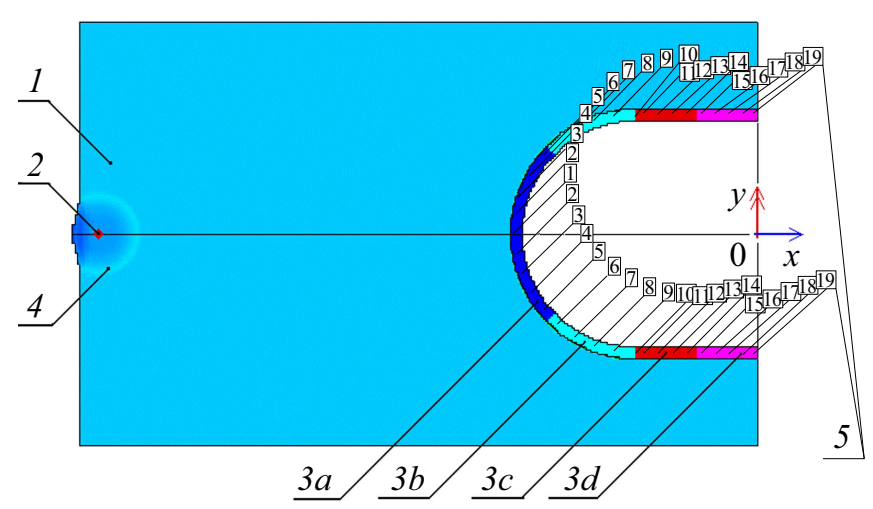

Рис. 1. Расчетная схема КЗ: $1-\mathrm{BB}, 2-$ точка инициирования, $3 a-3 d-\mathrm{KO}, 4-$ фронт детонационной волны, $5-$ реперные точки (маркеры или трассеры).

применения с точки зрения различных целей использования при решении задач в интересах, прежде всего, ракетно-космической отрасли, а также при исследовании поведения материалов при высокоскоростном соударении тел.

Известно, что для получения хорошего соответствия результатов расчета с экспериментальными данными по форме, скорости и целостности ВКЭ, в качестве моделей материала облицовки обычно используются модели сжимаемой прочной среды (упругопластической или упруговязкопластической) с учетом возможного разрушения материала [11].

Сложность процессов динамического деформирования ПЦ-облицовок, экстремальность условий, в которых происходит формирование ВКЭ, отсутствие достоверной информации о физико-механическом поведении материалов в этих условиях определили актуальность проведения анализа влияния физико-механических характеристик материала комбинированной КО на форму и скорость формируемого ВКЭ.

Основной задачей настоящих исследований являлось численное моделирование формирования ВКЭ с учетом критерия разрушения, а именно определение влияния таких параметров, как критическое значение интенсивности пластических деформаций и динамический предел текучести, на форму, массу и скорость формируемого ВКЭ.

Расчетная схема К3, включающая в себя заряд ВВ 1, точку инициирования заряда 2 и ПЦ-облицовку 3, разделенную на четыре части $3 a-3 d$, показана на рис. 1 . Такое представление облицовки позволяет в широких пределах варьировать физико-механическими параметрами используемого материала, задавая для одного и того же материала разные значения в различных частях облицовки, например, показатели прочности, критерии разрушения и т.п. Предполагалось, что в начальный момент времени $(t=0)$ в точке 2 осуществляется подрыв заряда $\mathrm{BB}$ с начальной плотностью $\rho_{\mathrm{BB}}$ и теплотой взрывчатого превращения $Q_{\text {вв. }}$ От точки инициирования распространяется фронт детонационной волны (ДВ) 4 со скоростью $D_{\mathrm{BB}}$ с образованием продуктов детонации (ПД). С течением времени ДВ отражается от поверхности облицовки, на которую действует давление порядка 35-60 GPa. Под действием ПД кумулятивная облицовка деформируется с образованием кумулятивной струи (КС), а впоследствии и ВКЭ.

Описанный процесс вполне обоснованно рассматривать в двумерной осесимметричной постановке в адиабатическом приближении, пренебрегая достаточно медленным процессом теплообмена частиц между собой. Кроме того, при рассмотрении подобных процессов, связанных с возникновением интенсивных полей напряжений, обычно пренебрегают действием внешних объемных сил типа сил тяжести. В качестве модели взаимодействующих между собой материалов элементов КО принималась модель идеальной упругопластической среды $[1,12,13]$. В этом случае система исходных уравнений базируется на фундаментальных законах сохранения массы, импульса и энергии, а также включает в себя уравнения состояния взаимодействующих тел; физические соотношения, конкретизирующие поведение упругопластичной среды и критерий ее разрушения.

Граничными условиями для данной задачи являются: условие симметрии на оси $y=0\left(v_{y}=0\right.$, см. рис. 1$)$; задание параметров Чепмена-Жуге на фронте ДВ [1]; на контактных границах металлических сред - равенство нормальных составляющих скоростей и напряжений; на границах типа „КО-ПД“, „КО-воздух“ $-\sigma_{n}=p$, где $p$ - давление в ПД или в воздухе, $\sigma_{n}$ - нормальные составляющие напряжения в текущем элементе облицовки. Предполагалось также, что в начальный момент времени ВВ детонирует в точке инициирования (2, рис. 1), рассматриваемые среды находятся в покое, а состояние их материалов соответствует невозмущенной среде.

Для получения более полной информации о параметрах напряженно-деформированного состояния и кинематических характеристиках движения элементов КО они маркировались реперными точками (маркерами или трассерами), в которых дополнительно вычислялись параметры текущего состояния среды. Расположение маркеров в расчетном поле схематично показано на рис. 1,5.

Динамический предел текучести $(Y)$ элементов КО в процессе проведения расчетных исследований принимался постоянным, а в качестве уравнений состояния для них использовались либо ударная адиабата вида $D_{\Phi}=a+b \cdot U$, позволяющая вычислить давление в ударно сжатом веществе посредством задания констант $a$ и $b[1]$, либо баротропная зависимость вида $p=K\left(\rho / \rho_{0}-1\right)$. Здесь $D_{\Phi}, a-$ скорости ударной волны и звука в материале, $b$ - коэффициент сжимаемости, $U-$ массовая скорость за фронтом ударной волны (табл. 1); $K$ - модуль объемного сжатия материала, рассчитываемый по значениям модуля Юнга и коэффициента Пуассона $K=E /[3(1-2 v)]$, где $E-$ модуль Юнга, v - коэффициент Пуассона. Принятые 
Таблица 1. Физико-механические характеристики используемых материалов КО

\begin{tabular}{|c|c|c|c|c|c|c|}
\hline \multirow{2}{*}{$\begin{array}{l}\text { № } \\
\Pi / \Pi\end{array}$} & \multirow{2}{*}{ Параметр } & \multicolumn{5}{|c|}{ Материал облицовки } \\
\hline & & Сталь 10, сталь 20 & Сталь 11ЮА & Железо ARMKO & Медь М1 & Алюминий (Амг-6) \\
\hline 1 & Плотность $\rho_{0}, \mathrm{~g} / \mathrm{cm}^{3}$ & 7.85 & 7.85 & 7.85 & 8.9 & 2.64 \\
\hline 2 & Скорость звука $a, \mathrm{~km} / \mathrm{s}$ & 3.94 & 3.94 & 3.8 & 3.98 & 5.5 \\
\hline 3 & Коэффициент сжимаемости, $b$ & 1.58 & 1.58 & 1.58 & 1.495 & 1.233 \\
\hline 4 & Модуль объемного сжатия $K, \mathrm{GPa}$ & 166.7 & 166.7 & 166.7 & 152.8 & 60.5 \\
\hline 5 & Модуль сдвига $G, \mathrm{GPa}$ & 81.4 & 81.4 & 81.4 & 39.9 & 26.3 \\
\hline 6 & $\begin{array}{l}\text { Динамический предел } \\
\text { текучести } Y, \mathrm{GPa}\end{array}$ & $0.5-1.1$ & $0.5-0.65$ & $0.2-0.3$ & 0.25 & 0.3 \\
\hline 7 & Откольная прочность $\sigma^{*}, \mathrm{GPa}$ & 1.65 & 1.65 & 1.65 & 1.2 & - \\
\hline 8 & Относительное сужение $\psi, \%$ & 55 & 73 & 90 & 75 & $40-90$ \\
\hline 9 & $\begin{array}{l}\text { Предельные значения } \\
\text { пластических деформаций } \varepsilon^{*}\end{array}$ & $1.4-1.95$ & $2.6-3.2$ & $2.8-4.6$ & $3.2-4.0$ & $1.2-4.6$ \\
\hline
\end{tabular}

числовые значения физико-механических характеристик для перечисленных материалов представлены в табл. 1.

Во всех проведенных расчетах был задан одинаковый октогеносодержащий состав ВВ (содержание октогена 94\%) - PBX-9404 со следующими характеристиками: $\rho_{\mathrm{BB}}=1.84 \mathrm{~g} / \mathrm{cm}^{3}, D_{\mathrm{BB}}=8.8 \mathrm{~km} / \mathrm{s}, Q_{\mathrm{BB}}=5.53 \mathrm{MJ} / \mathrm{kg}$ и $P=37 \mathrm{GPa}$ (давление Чепмена-Жуге).

В качестве материалов облицовок рассматривались сталь, алюминий и медь. Было проведено моделирование формирования ВКЭ при использовании меди марки М1, алюминия Амг-6 и стали разных марок: сталь 10, 20, 11ЮА, технически чистое железо (железо ARMKO). Ocновные характеристики материалов приведены в табл. 1.

Для описания разрушения элементов КО в процессе формирования ВКЭ использовалась комбинация критериев откольной прочности $\sigma_{i}=\sigma^{*}\left(\sigma_{I}-\right.$ интенсивность напряжений, $\sigma^{*}$ - откольная прочность (см. табл. 1)) и предельных пластических деформаций $\varepsilon_{i}=\varepsilon^{*}\left(\varepsilon_{i}-\right.$ интенсивность деформаций, $\varepsilon^{*}-$ предельная пластическая деформация (см. табл. 1) [11]. При этом прочностной критерий использовался на этапе взаимодействия КО с детонационной волной, а деформационный - при последующем деформировании КО и формировании ВКЭ. В качестве критических значений пластических деформаций можно рекомендовать величину $\varepsilon^{*}=\eta \ln (1 /(1-\psi))$, где $\psi$ - относительное сужение материала образца (см. табл. 1$) ; \eta-$ эмпирический коэффициент. В первом приближении его числовые значения можно принять изменяющимися в диапазоне от $\eta \approx 2$ до $\approx \sqrt{6} \approx 2.45[13,14]$. В более общем случае их можно подобрать расчетным путем с использованием экспериментальных данных, примерно таким же образом, как это сделано в работе [11].

Прочностной критерий ограничивает растягивающие напряжения $\sigma_{i}>\sigma_{p}^{*}$, где $\sigma_{i}, \sigma_{p}^{*}-$ соответственно интенсивность напряжений и его предельное значение, различные для разных материалов. Для одноосного напряженно-деформированного состояния $\sigma_{i}=\sigma_{1}$, где $\sigma_{1}$ - главное растягивающее напряжение. При выпол- нении данного условия в областях растяжения $(p<0$, $p$ - гидростатическое давление) материал теряет свою прочность $Y=0$ и при повторном нагружении ведет себя как сыпучее тело.

К аналогичному виду критериев можно отнести критерий вида $p<p^{*}$, ограничивающий нижний порог давления в областях растяжения $(p<0)$. Здесь $p^{*}-$ предельное значение давления, ниже которого материал теряет свою прочность [13]. Пороговые значения давления в первом приближении можно рассчитать также как и для одноосного растяжения $p_{0}^{*}=-\sigma_{p}^{*}+(2 / 3) Y$, где $\sigma_{p}^{*}-$ откольная прочность [11].

Деформационный критерий был выбран для моделирования формирования ВКЭ, согласно которому разрушение материала происходит при достижении интенсивностью деформаций своих критических значений $\varepsilon^{*}$. Деформационный критерий можно описать соотношением $\varepsilon_{i} \geq \varepsilon^{*}$, где $\varepsilon_{i}=\sqrt{2 / 3} \sqrt{\varepsilon_{p}^{i j} \varepsilon_{p}^{i j}}$ или $\varepsilon_{i}=\sqrt{2 / 3} \int \sqrt{\dot{\varepsilon}^{i j} \dot{\varepsilon}^{i j}} d t-$ интенсивность пластических деформаций; $\varepsilon^{i j}, \dot{\varepsilon}^{i j}-$ соответственно пластические составляющие компонент тензора деформаций и тензора скоростей деформаций; $\varepsilon^{*}$ - предельная (критическая) пластическая деформация.

Конкретные расчеты проводились на примере К3 со следующими геометрическими характеристиками: диаметр заряда $90 \mathrm{~mm}$, высота заряда $144 \mathrm{~mm}$, внутренний диаметр облицовки $48 \mathrm{~mm}$, высота облицовки $50 \mathrm{~mm}$, толщина стальной облицовки $2.5 \mathrm{~mm}$ (базовый КЗ, используемый в работе [3]). Толщины медной и алюминиевой облицовок определялись исходя из равенства масс таких облицовок массе стальной КО. Результаты расчетов представлены на последующих рисунках. При численном моделировании процесса схлопывания ПЦ-облицовки и формирования ВКЭ с учетом комбинации критериев разрушения определялись зоны пластических деформаций материала комбинированной КО при функционировании КЗ.

На рис. 2 представлены характерные стадии деформирования и разрушения стального ВКЭ, полученные с ис- 


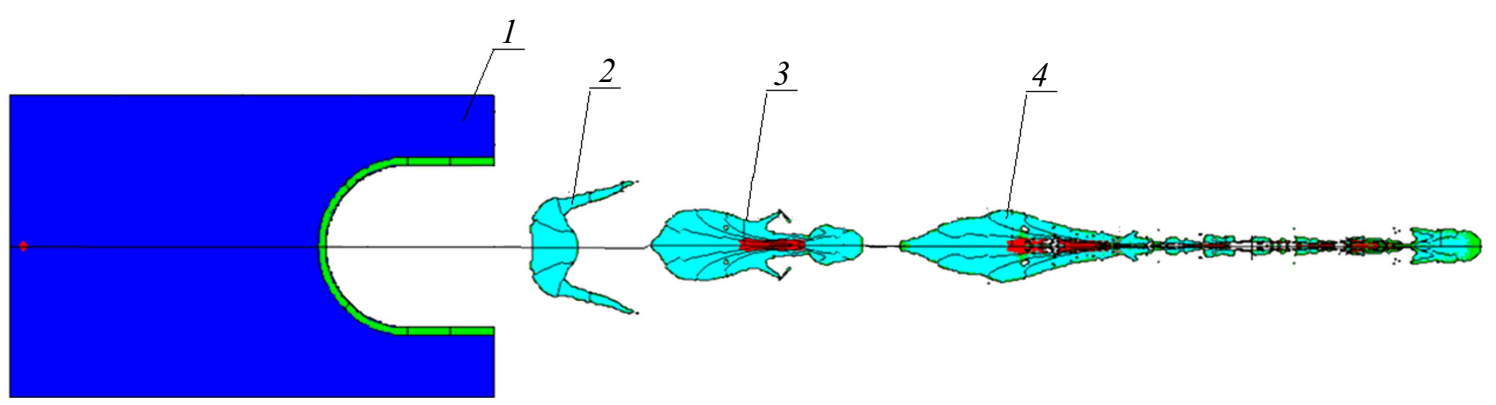

Рис. 2. Характерные стадии деформирования и разрушения стального ВКЭ, полученные расчетным путем с использованием комбинированного критерия разрушения $Y=0.3 \mathrm{GPa}, \varepsilon^{*}=4.6$ для моментов времени: $1-0,2-20,3-30$ и $4-50 \mu \mathrm{s}$.

пользованием комбинированного критерия разрушения $Y=0.3 \mathrm{GPa}, \varepsilon^{*}=4.6$ для различных моментов времени. Разными оттенками выделены зоны материала для различных стадий деформирования. Наиболее темным цветом - области, где материал разрушен; серым зоны безградиентного (в головной части) и низкоградиентного потоков (в хвостовой части) соответственно. Область разрушения элемента зарождается в центральной зоне потока вблизи оси симметрии. В результате образуется явно выраженный головной безградиентный элемент, низкоградиентный хвостовой элемент и множество разрушенных центральных элементов, что хорошо согласуется с экспериментальными данными.

Применение комбинированного критерия является для данных задач более универсальным, так как кроме этапа растяжения элемента под действием градиента скоростей обеспечивается контроль напряженнодеформированного состояния ПЦ-облицовки на этапе взаимодействия с ДВ на начальной стадии своего движения.

При моделировании процесса формирования ВКЭ для сравнения рассматривались медные, стальные и алюминиевые комбинированные ПЦ-облицовки. Следует отметить, что в расчетах конструкция заряда, габариты и тип ВВ оставались неизменными, ПЦ-облицовка имела постоянную толщину струеобразующей части, как и у базового заряда, варьировалась только толщина КО для различных материалов. Расчеты проводились в программном комплексе ANSYS Autodyn. Значения параметров КО для различных численных экспериментов приведены в табл. 2-4.

Для определения расположения элементов КО в процессе схлопывания и образования ВКЭ положение соответствующих элементов облицовки при постановке задачи задавалось различными, в то же время для определения параметров формирующегося струйного течения вдоль КО были установлены лагранжевы датчики (рис. 1).

На рис. 3 представлены результаты четырех численных экспериментов для формирования стальных ВКЭ, варьируемые параметры которых представлены в табл. 2. Темным цветом показан материал купольной части КО, участвующий в формировании ВКЭ. Масса формируе-
Таблица 2. Параметры стальной КО для различных численных экспериментов

\begin{tabular}{|c|c|c|c|c|c|}
\hline $\begin{array}{c}\text { Номер } \\
\text { численного } \\
\text { эксперимента }\end{array}$ & $\varepsilon^{*}$ & $\begin{array}{c}Y, \\
\mathrm{GPa}\end{array}$ & $\begin{array}{l}\text { Соответствие } \\
\text { материалу КО }\end{array}$ & $\begin{array}{l}V_{\mathrm{VKE}} \\
\mathrm{km} / \mathrm{s}\end{array}$ & $\begin{array}{c}M_{\mathrm{VKE}}, \\
\mathrm{g} / \rho, \\
\mathrm{g} / \mathrm{cm}^{3}\end{array}$ \\
\hline 1 & 1.4 & 0.5 & Сталь 10, 20 & 6.0 & $6.58 / 7.34$ \\
\hline 2 & $\begin{array}{l}\text { Без раз- } \\
\text { рушения }\end{array}$ & 0.5 & Сталь 10, 20 & 6.0 & $15.67 / 7.47$ \\
\hline 3 & $3.0-3.6$ & 0.5 & Сталь 11ЮА & 6.0 & $10.46 / 7.84$ \\
\hline 4 & 4.6 & 0.3 & $\begin{array}{c}\text { Железо } \\
\text { ARMCO }\end{array}$ & 6.0 & $16.64 / 7.66$ \\
\hline
\end{tabular}

мых стальных ВКЭ приведена в табл. 2 и находится в диапазоне $6.58-16.64 \mathrm{~g}$.

Благодаря введению в расчетные модели различных геометрических зон ПЦ-облицовок, видно, материал какой части облицовки в результате схлопывания переходит в безградиентный ВКЭ. В данном случае в ВКЭ идет материал купольной части ПЦ-облицовки (представлено черным цветом). Цилиндрическая часть полностью участвует в процессе отсечки ВКЭ и разрушается в процессе полета, зона сопряжения струеобразующей и отсекающей частей (отмечены серым цветом) переходит как в ВКЭ, так и в хвостовую разрушающуюся часть потока.

Проведя сравнение между полученными результатами моделирования можно отметить, что наиболее подходящий вариант ВКЭ, обладающий наибольшей массой, был получен при использовании в качестве материала облицовки железа ARMCO, т.е. вариант расчета № 4 (рис. 3). Указанный вариант стальной КО имел минимальный из рассмотренных динамический предел текучести $(Y=0.3 \mathrm{GPa})$ и наибольшее значение интенсивности пластических деформаций $\left(\varepsilon^{*}=4.6\right)$, т.е. используемый материал был наиболее пластичным.

Сравнение результатов численных расчетов процесса схлопывания стальных комбинированных КО постоянной толщины с учетом критерия разрушения с известными результатами расчетов без учета критерия разрушения показало, что введение критерия разрушения в 


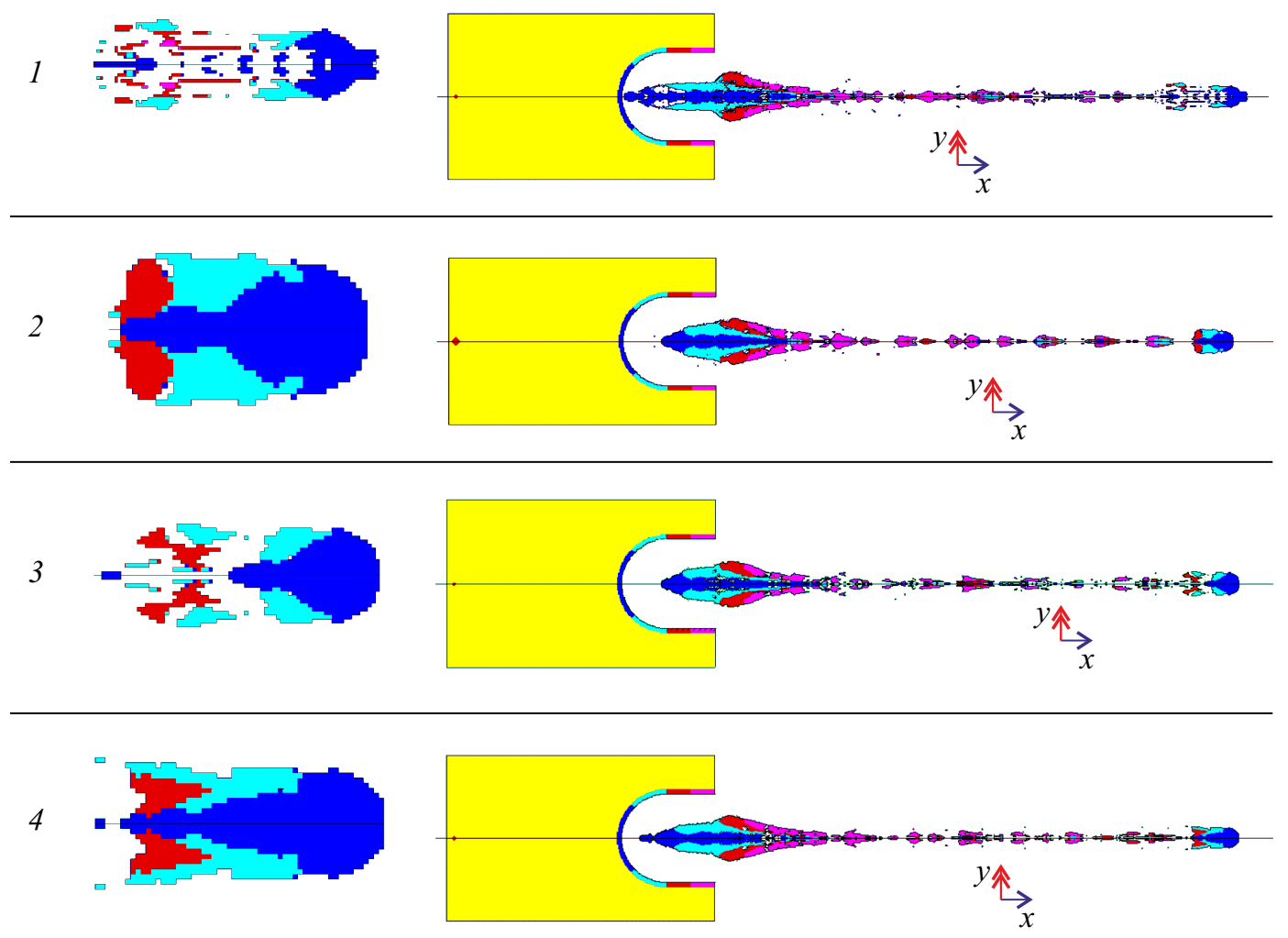

Рис. 3. Процесс формирования стального ВКЭ для различных значений физико-механических характеристик материала.

Таблица 3. Параметры медной КО для различных численных экспериментов

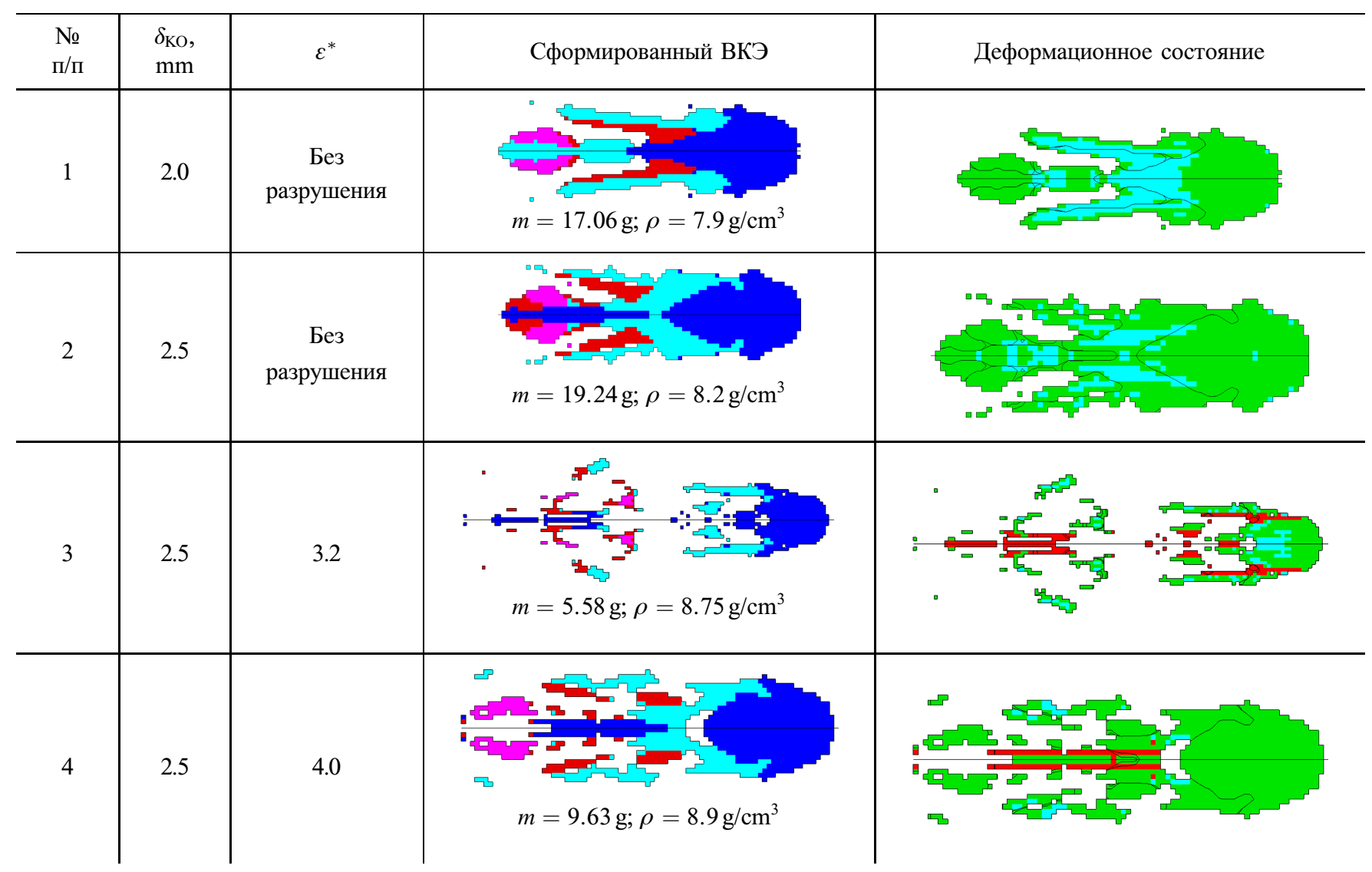




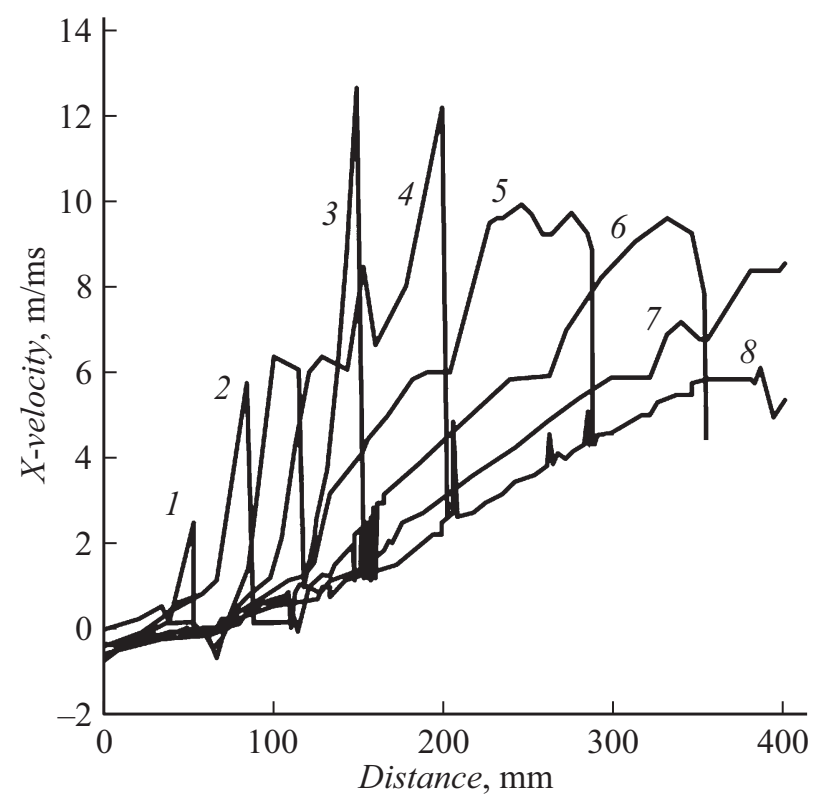

Рис. 4. Характер изменения скорости потока, формирующегося при схлопывании стальной КО постоянной толщины: 1 $12,2-20,3-25,4-30,5-40,6-50,7-60.8-$ $70 \mu \mathrm{s}$.

численное моделирование не оказывает значительного влияния на скорость сформированного безградиентного компактного элемента. Так, например, для приведенных расчетов с различными величинами прочности и пластичности скорость стального ВКЭ составила $6 \mathrm{~km} / \mathrm{s}$, как и для случая расчета базового заряда [5]. Исходя из результатов анализа пластического состояния частей высокоскоростного потока (рис. 2) видно, что окончательное формирование стального безградиентного ВКЭ произошло в момент времени $50 \mu \mathrm{s}$. При рассмотрении значений скорости потока для различных моментов времени (рис. 4) видно, что для указанного момента времени $(50 \mu \mathrm{s})$ в зоне формирования ВКЭ значение скорости составляет $6 \mathrm{~km} / \mathrm{s}$, и график скорости имеет постоянное значение (выходит на насыщение). Данная картина подтверждает факт формирования безградиентного компактного элемента и сохранения данных значений скорости безградиентного ВКЭ на последующих моментах времени. Полученные значения скорости $(6 \mathrm{~km} / \mathrm{s})$ полностью согласуются с экспериментальными данными [3].

Как видно из результатов (рис. 3, табл. 2), различные соотношения таких параметров, как критическое значение интенсивности пластических деформаций и динамический предел текучести, не оказывают влияние на скорость сформированного стального ВКЭ, но оказывают существенное влияние на его массу и форму.

Также одним из интересных результатов данных исследований является то, что удалось определить соотношение между элементами стальной комбинированной КО до начала схлопывания с элементами струйного
Таблица 4. Параметры алюминиевой КО для различных численных экспериментов

\begin{tabular}{c|c|c|c|c}
\hline $\begin{array}{c}\text { Номер } \\
\text { численного } \\
\text { эксперимента }\end{array}$ & $\varepsilon^{*}$ & $\begin{array}{c}\delta_{\mathrm{KO}}, \\
\mathrm{mm}\end{array}$ & $\begin{array}{c}V_{\mathrm{VKE}}, \\
\mathrm{km} / \mathrm{s}\end{array}$ & $\begin{array}{c}M_{\mathrm{VKE}}, \mathrm{g} / \rho, \\
\mathrm{g} / \mathrm{cm}^{3}\end{array}$ \\
\hline 1 & Без разрушения & 6.6 & 7.0 & $11.66 / 2.51$ \\
2 & 4.6 & 6.6 & 7.0 & $9.18 / 2.53$ \\
3 & 3.2 & 6.6 & 7.0 & $9.3 / 2.46$ \\
4 & 2.1 & 6.6 & 7.0 & $5.2 / 2.38$
\end{tabular}

течения в момент формирования ВКЭ. Видно, что в формировании ВКЭ участвует лишь сегмент полусферической (струеобразующей) части облицовки, в то время как отсекающая цилиндрическая часть полностью разрушается в процессе схлопывания. Расположение элементов комбинированной КО после процесса схлопывания показано на рис. 3 .

Рассмотрим процесс формирования ВКЭ для медной комбинированной КО. Физико-механические характеристики задаваемого материала приведены в табл. 1, для всех численных экспериментов параметр $Y$ оставался неизменным и составлял $Y=0.25 \mathrm{GPa}$. Для моделирования формирования ВКЭ принят материал, соответствующий меди М1. Толщина медной КО была определена из условия равенства масс стальной КО и медной КО.

Из представленных в табл. 3 результатов видно, что введение критерия разрушения оказывает влияние на форму и размеры получаемого медного ВКЭ. Деформационное состояние, показанное в табл. 3 серым цветом, соответствует безградиентным зонам течения, в то время как черным - зоны интенсивных деформаций и разрушения. Скорость сформированного ВКЭ для всех рассмотренных вариантов (табл. 3) оставалась неизменной и составляла $5.9 \mathrm{~km} / \mathrm{s}$. Следует отметить, что наиболее массивный медный элемент формируется для наибольшего значения предельных пластических деформаций $\varepsilon^{*}=4$. Масса данного ВКЭ по результатам численного моделирования с учетом критерия разрушения составила $9.63 \mathrm{~g}$.

Рассмотрим влияние критерия разрушения на формирование ВКЭ из алюминиевой КО. В табл. 4 приведены параметры, варьируемые в различных экспериментах, при этом для всех численных экспериментов параметр $Y$ оставался неизменным и составлял $Y=0.3 \mathrm{GPa}$. Толщина алюминиевой КО в расчетах составляла $\delta_{\text {Ко }}=6.6 \mathrm{~mm}$ и была определена из условия равенства масс стальной КО и алюминиевой КО. На рис. 5 приведено сопоставление ВКЭ, сформированных из алюминиевой КО для различных частей облицовки. Из результатов численных расчетов моделирования формирования алюминиевого ВКЭ с учетом критерия разрушения видно, что наиболее массивный элемент по соотношению массы и плотности также формируется для наибольшего $\varepsilon^{*}$ (вариант 3: $M_{\mathrm{VKE}}=9.3 \mathrm{~g}, \varepsilon^{*}=3.2$ ) (табл. 4). При этом все при- 

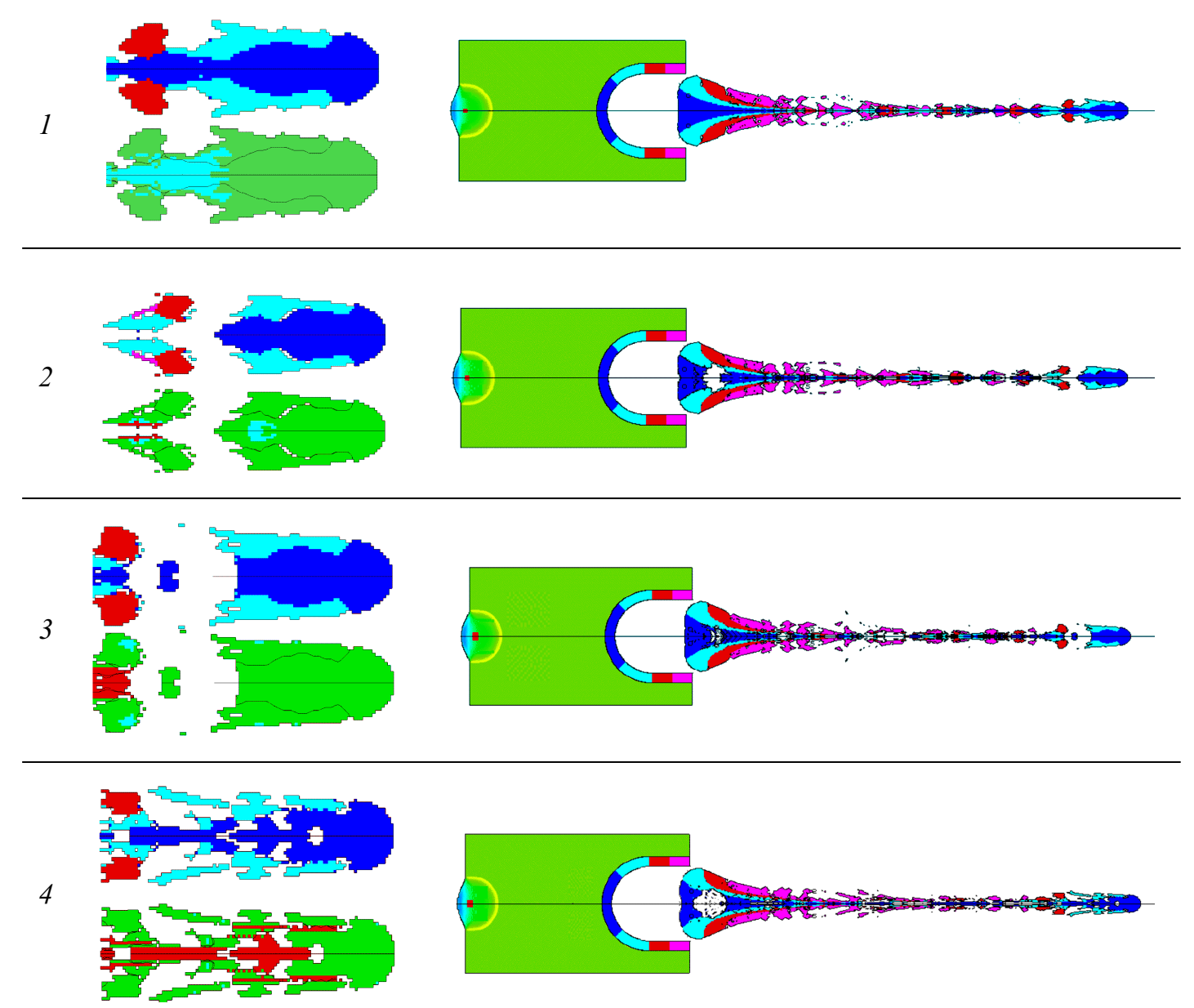

Рис. 5. Процесс формирования алюминиевого ВКЭ для различных значений вариантов численных экспериментов (табл. 4).

веденные расчеты подтверждают отсутствие влияние критерия разрушения на скорость формируемого безградиентного ВКЭ.

В результате рассмотрения различных вариантов численного моделирования для меди, стали и алюминия можно сделать вывод, что для анализа изменения $M_{\mathrm{VKE}}$ следует анализировать комплекс из трех параметров: плотность, прочность и пластичность $\left(\rho_{\text {Ко }}, Y, \varepsilon^{*}\right)$. Так, в приведенных результатах численного моделирования с учетом критерия разрушения, максимальные значения

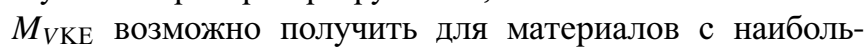
шим значением $\varepsilon^{*}$. Для рассмотренных материалов КО (сталь, медь, алюминий) наиболее массивный ВКЭ формируется для стальных КО. Именно поэтому для получения массивных безградиентных высокоскоростных компактных элементов рекомендуется использовать стальные КО. Повышение актуальности данных исследований также обусловлено увеличением доли стальных элементов среди осколков космического мусора, что подтверждено отчетом Ordem 3.0 международного комитета NASA.

Проведение численного моделирования процесса схлопывания медных, стальных и алюминиевых комби- нированных КО с учетом критерия разрушения позволило определить влияние физико-механических характеристик материала на скорость, форму и массу ВКЭ, а также показать, что введение критерия разрушения не оказывает влияния на скорость формируемого потока, однако оказывает существенное влияние на форму и массу ВКЭ.

Работа выполнена при финансовой поддержке Министерства образования и науки Российской Федерации в рамках базовой части государственного задания по разделу „Инициативные научные проекты“ (код проекта 9.5330.2017 БЧ).

\section{Список литературы}

[1] Физика взрыва / Под ред. Л.П. Орленко. Изд. 3-е, испр. В 2-х т. Т. 2. М.: Физматлит, 2004. 656 с.

[2] Орленко Л.П. Физика взрыва и удара. Уч. пос. для вузов. 2-е изд., испр. М.: Физматлит, 2008. 304 с.

[3] Жданов И.В., Князев А.С., Маляров Д.В. // Тр. Томского гос. ун-та. Сер. физ.-мат. 2010. Т. 276. С. 193-195. 
[4] Голденко Н.А., Грязнов Е.Ф., Судомоев А.Д., Фельдштейн B.A. // Космонавтика и ракетостроение. 2016. № 7 (92). C. 42-47.

[5] Федоров С.В., Баянова Я.М., Ладов С.В. // Физика горения и взрыва. 2015. Т. 51. № 1. С. 150-164. [Fedorov S.V., Bayanova Y.M., Ladov S.V. // Combustion, Explosion, and Shock Waves. 2015. Vol. 51. N 1. P. 130-142.]

[6] Selivanov V.V., Fedorov S.V., Nikolskaya Ya.M., Ladov S.V. // Acta Astronaut. 2017. Vol. 135. N 10. P. 34-43. DOI: $10.1016 \mathrm{j}$ actaastro.2016.10.025

[7] Fedorov S.V., Ladov S.V., Nikolskaya Ya.M. // J. Phys. Conf. Ser. 2017. Vol. 894. N 1. P. 012066. DOI: $10.1088 / 1742-6596 / 894 / 1 / 012066$

[8] Федоров С.В. // Физика горения и взрыва. 2016. Т. 52. № 5. C. 116-130. [Fedorov S.V. // Combustion, Explosion, and Shock Waves. 2016. Vol. 52. N 5. P. 600-612.]

[9] Федоров С.В. // Вестник МГТУ им. Н.Э. Баумана. Сер. Естественные науки. 2017. № 3 (72). С. 71-92.

[10] Федоров С.В., Ладов С.В., Никольская Я.М., Баскаков В.Д., Бабурин М.А., Курепин А.Е., Горбунков А.А., Пирозерский А.С. // Физика горения и взрыва. 2017. Т. 53. № 4. C. 122-125. [Fedorov S.V., Ladov S.V., Nikol'skaya Y.M., Baskakov V.D., Baburin M.A., Kurepin A.E., Gorbunkov A.A., Pirozerskii A.S. // Combustion, Explosion, and Shock Waves. 2017. Vol. 53. N 4. P. 479-482.]

[11] Колпаков В.И. // Тр. межд. конф. ХІІІ Харитоновские тематические научные чтения. Саров: Россия, 2011. С. 532 536.

[12] Теоретические и экспериментальные исследования высокоскоростного взаимодействия тел / Под ред. А.В. Герасимова. Томск: Том. ун-т, 2007. 572 с.

[13] Бабкин А.В., Колпаков В.И., Охитин В.Н., Селиванов В.В. Численные методы в задачах физики быстропротекающих процессов. Учебник для втузов. 2-е изд., испр. М.: МГТУ им. Н.Э. Баумана, 2006. 520 с.

[14] Селиванов В.В. Механика разрушения деформируемого тела. Уч. изд. для втузов. 2-е изд., испр. М.: МГТУ им. Н.Э. Баумана, 2006. 424 с. 